\title{
PELANGGARAN DAN PEMATUHAN PRINSIP KERJASAMA PADA TUTURAN HUMOR TENSAI BAKABON VOLUME 2 KARYA FUJIO AKATSUKA
}

\author{
P.Fatmawati ${ }^{1}$, G.S.Hermawan ${ }^{2}$, D.S.Mardani ${ }^{3}$ \\ 123 Jurusan Pendidikan Bahasa Jepang, Universitas Pendidikan Ganesha, Singaraja,Bali \\ e-mail: puputsquarepants@gmail.com, satya.hermawan@undiksha.ac.id, desak.mardani@undiksha.ac.id
}

\begin{abstract}
Abstrak
Penelitian ini bertujuan untuk mengetahui teknik humor dilihat dari segi kebahasaan dan bentuk pelanggaran maupun pematuhan prinsip kerjasama dalam manga Tensai Bakabon Volume 2. Penelitian ini menggunakan teori prinsip kerjasama yang dikemukakan oleh Grice (1975) dan teori teknik humor menurut Berger (1992). Data dalam penelitian ini diperoleh dengan menggunakan metode simak dan teknik catat kemudian dianalisis dengan metode deskriptif kualitatif. Hasil yang ditemukan yaitu 9 teknik humor yang digunakan yaitu teknik kesalahpahaman, melebih-lebihkan, harfiah, membual, sindiran, kekanak-kanakan, permainan kata, hinaan, jenaka. Total data yaitu 26 data pelanggaran terhadap prinsip kerjasama dan 2 data pematuhan prinsip kerjasama yang memunculkan efek humor dalam manga tersebut.
\end{abstract}

Kata Kunci: pragmatik, teknik humor, prinsip kerjasama.

\section{要旨}

本研究は、赤塚不二夫原作漫画『天才バカボン』第二巻のユーモア描写場面での言 語面で見たユーモアテクニックと協調原理の違反及び順守を思うかにすることである。本論 では、Griceの協調理論（1975）及びBergerのユーモア論(1992) を参考にした。データは、 視聴および表記により収集し、定性的記述法により分析した。結果は、ユーモア描写場面 は、誤解、誇張、文字通り、自慢、風刺、幼稚性、言葉遊び、侮辱、滑稽の10種類のユーモ ア技法をしよるしていることと考えさせる。協調原理の違反に相当するものが26例、順守に 相当するものは2例であり、この漫画のユーモア効果を高めていると言える。

キーワード : 語用論、ユーモアのテクニック、協調原理。

\section{Pendahuluan}

Dalam kehidupan sehari-hari setiap orang pasti pernah berhumor, ada yang memiliki selera humor tinggi dan ada juga yang memiliki selera humor biasa saja bahkan rendah. Ada yang memendamnya karena malu, ada juga yang berani mengekspresikannya secara langsung.

Ariefandi (2015) menyatakan bahwa dalam humor dibutuhkan kecerdasan kedua belah pihak, yaitu penutur dan mitra tutur. Penutur dituntut agar bisa menempatkan humornya pada waktu yang tepat, sebab apabila waktunya tidak tepat, humor tersebut dapat menjadi tidak lucu bahkan juga bisa menyakiti pihak lain. Selain itu, mitra tutur juga dituntut agar bisa bersikap dewasa dalam menanggapi sebuah humor, karena bagaimanapun tajamnya kritikan dalam sebuah humor, humor tetaplah humor.

Salah satu media penyampaian humor adalah media cetak yaitu komik. Menurut Kamus Besar Bahasa Indonesia Online (2012) komik adalah cerita bergambar di majalah, surat kabar, atau berbentuk buku yang umumnya mudah dicerna dan lucu. Komik adalah suatu bentuk seni yang menggunakan gambar-gambar tidak bergerak yang disusun sedemikian rupa sehingga membentuk jalinan cerita. Biasanya, komik dicetak dan diterbitkan di atas 
kertas dan dilengkapi dengan teks. Komik dapat diterbitkan dalam berbagai bentuk, mulai dari strip dalam koran, dimuat dalam majalah, hingga berbentuk buku tersendiri.

Humor dalam manga biasanya terletak pada perilaku tokoh dan tuturan tokoh yang menampilkan sesuatu yang mengandung kelucuan yang membuat pembaca tertawa ketika menikmati komik tersebut. Aspek kelucuan atau humor tersebut dapat diperoleh dari berbagai cara seperti lewat sikap masing-masing tokoh yang terkesan lucu, aneh, dan unik yang dituangkan dalam bentuk gambar-gambar lucu baik dilihat dari segi potongan, ukuran tubuh, tampang, proporsionalitas bagian-bagian tubuh atau bentuk-bentuk bagian tubuh yang lebih sering terlihat aneh maupun tuturan-tuturan tokoh yang terkesan janggal dan terkadang terlalu apa adanya dalam berkomunikasi. Salah satu manga humor yang terkenal di Jepang yaitu Tensai Bakabon (天才バカボン) karya Fujio Akatsuka, komik ini pertama kali muncul di Jepang pada tahun 1967, diterbitkan di majalah komik mingguan Shonen Shukan. Dalam komik Tensai Bakabon (天才バカボン), terdapat beberapa tokoh, seperti Papa Bakabon, Bakabon, Mama Bakanbon, Omawari-san, Hajime, dan lain-lain. Tema utama dalam cerita ini tentang kebodohan yang diperlihatkan oleh masing-masing tokohnya. Tokoh yang paling sering melakukan kebodohan dalam cerita ini adalah Papa Bakabon. Kekonyolan dalam cerita Bakabon mengambil setting kehidupan sehari-hari masyarakat Jepang.

Keunikan yang dimiliki manga humor Tensai Bakabon yaitu tuturan yang digunakan para tokoh dalam berkomunikasi benar-benar diluar dugaan pembaca yang biasanya dalam sebuah komik tuturan yang digunakan para tokoh mudah ditebak sehingga tidak menarik minat pembaca untuk membaca komik tersebut. Selain itu, komik ini tidak seperti komik lainya, yang mengutamakan gambar daripada tuturannya. Selain itu bentuk-bentuk tuturan yang disampaikan tokoh Papa dan juga Bakabon serta tokoh lainnya di dalam komik yang terkesan janggal dan terkadang tuturannya disampaikan dengan apa adanya, yang tuturan tersebut justru dapat memunculkan kelucuan yang dapat membuat para pembaca tertawa ketika membacanya. Bentuk tuturan yang disampaikan secara janggal akan menyebabkan pelanggaran terhadap prinsip kerjasama sedangkan bentuk tuturan yang disampaikan dengan apa adanya akan menyebabkan pematuhan terhadap prinsip kerjasama.

Berdasarkan pemaparan di atas, penulis bermaksud untuk melaksanakan penelitian tentang pelanggaran dan pematuhan prinsip kerjasama pada tuturan humor yang ada pada komik Tensai Bakabon Vol.2 karya Fujio Akatsuka dengan rumusan masalah sebagai berikut :

1. Apa saja teknik penciptaan humor dilihat dari segi kebahasaan yang digunakan tokoh untuk memunculkan tuturan humor dalam manga humor Tensai Bakabon (天才バカボン) Volume 2 karya Fujio Akatsuka?

2. Bagaimana bentuk pelanggaran dan pematuhan prinsip kerjasama dalam manga humor Tensai Bakabon (天才バカボン) Volume 2 karya Fujio Akatsuka?

\section{Pengertian Pragmatik}

Menurut Hayashi (1990:171) mendefinisikan pragmatik atau goyouron adalah sebagai berikut.

言語とそれが使われる場面、状況との関連を理論的に扱うのが語用論と言える。

\section{“Kengoto sorega tsugawareru bamen, jyoukyoutono kanrenwo rirontekini atsukaunoka goyouronto ieru."}

Yang disebut dengan pragmatik adalah ilmu yang mebahas secara teoritis hubungan bahasa dengan adegan atau situasi dimana bahasa tersebut digunakan.

Berdasarkan teori tersebut dapat disimpulkan bahwa pragmatik adalah cabang ilmu bahasa yang mempelajari bahasa yang digunakan untuk berkomunikasi dalam situasi tertentu yang terikat konteks/mengkaji maksud penutur. 


\section{Prinsip Kerjasama}

Prinsip kerjasama menurut Grice (1975) yaitu :

"Make your conversational contribution such as required, at the stage at which it occurs, by the acdepted purpose or direction of the talk exchange in which you are engaged!"

(Buatlah sumbangan percakapan anda seperti yang diinginkan pada saat berbicara, berdasarkan tujuan percakapan yang disepakati atau arah perakapan yang sedang anda ikuti).

Jadi prinsip kerjasama adalah aturan yang baik dalam berkomunikasi yang digunakan dalam percakapan yang ideal, sehingga informasi yang didapatkan sesuai dengan kebutuhan penutur ataupun mitra tutur.

Grice (1975:45-47) mengemukakan bahwa dalam prinsip kerjasama terdapat empat maksim, yaitu maksim kualitas, maksim kuantitas, maksim relevansi, dan maksim cara. Maksim-maksim tersebut merupakan unsur dalam percakapan baik dipatuhi atau tidak akan mempengaruhi tuturan.

Berikut penjelasan maksim- maksim tersebut sesuai dengan penjelasan Koizumi (2001:41-48).

1. Maksim Kualitas (質の公理)

Maksim Kualitas adalah aturan dalam tuturan dimana peserta tutur dituntut untuk membuat suatu tuturan atau informasi yang terbukti secara fakta.

2. Maksim Kuantitas (量の公理)

Maksim kuantitas adalah aturan dalam tuturan untuk memberikan jumlah informasi yang tepat, tidak boleh melebihi informasi yang sebenarnya dibutuhkan mitra tutur.

3. Maksim Relevansi (関係の公理)

Maksim relevansi adalah jenis aturan dalam prinsip kerjasama yang mengatur setiap peserta percakapan, memberikan kontribusi yang relevan dan saling berkesinambungan antara informasi yang diminta dengan informasi yang akan diberikan terhadap situasi pembicaraan.

4. Maksim Cara (様態の公理)

Di dalam maksim cara peserta tutur diharuskan agar setiap tuturannya agar mudah dimengerti atau mengatakan sesuatu dengan jelas.

\section{Konteks}

Konteks adalah sesuatu yang menyertai atau bersama teks dan menjadi lingkungan atau situasi penggunaan bahasa (Rani dkk, 2004:190). Menurut Hymes (dalam Chaer dan Leonie, 2004: 48-49) terdapat faktor-faktor yang mempengaruhi konteks (model of SPEAKING) yaitu :

a) Setting atau Scene (latar tuturan)

Setting yaitu waktu dan tempat tutur berlangsung, sedangkan scene merupakan situasi psikologis pembicara.

b) Participant (penutur, mitra tutur, dan seterusnya)

Paticipants adalah pihak-pihak yang terlibat dalam pertuturan.

c) Ends (tujuan)

Ends, merujuk pada maksud dan tujuan pertuturan.

d) Act sequence (tindakan penutur)

Act sequence, mengacu pada bentuk ujaran dan isi ujaran.

e) Key (nada atau ragam bahasa)

Key, mengacu pada nada, cara, dan semangat

f) Instrumentalies (alat komunikasi)

Instrumentalies, mengacu pada jalur bahasa yang digunakan.

g) Norm of Interaction and Interpretation (aturan dalam bertutur)

Norm of Interaction and Interpretation, mengacu pada norma atau aturan dalam berinteraksi.

h) Genre (jenis kegiatan komunikasi)

Genre, mengacu pada jenis bentuk penyampaian. 


\section{Implikatur}

Menurut Bussmann (1996 : 220-221) menjabarkan implikasi dalam lima konsep.

a. Material Implication, yakni implikasi digunakan untuk membahas kebenaran dan kesalahan suatu fakta yang disesuaikan dengan tuturannya.

b. Logical Implication yakni hubungan metalinguistik antara dua proporsisi atau lebih.

c. Strict Implication, yakni hubungan implikasional dalam logika modalitas.

d. Semantic Implication, yakni interpretasi lebih tajam mengenai makna berdasarkan bahasa natural.

e. Contextual Impliction, yakni pelebaran konsep implikasi dengan aspek pragmatik.

Menurut Brown dan Yule (1988: 31) yang juga berdasar teori Grice, Bahwa istilah implikatur dipakai untuk menerangkan apa yang mungkin diartikan, disarankan, atau dimaksud oleh penutur yang berbeda dengan apa yang sebenarnya yang dikatakan oleh penutur.

\section{Humor}

Menurut Hamlyn (1995:806) menulis bahwa humor itu berupa kemampuan menghibur dan menggelikan melalui ujaran atau tulisan. Humor menjadi tidak lucu jika tidak dimengerti, ada rasa antipati, menyinggung perasaan, salah tempat, waktu, dan situasi.

Humor dapat diklasifikasikan menjadi dua tipe berdasarkan bentuknya, yaitu humor verbal dan humor nonverbal. Humor verbal adalah humor yang dipresentasikan dengan kata-kata, sedangkan humor non verbal dengan gerak-gerik atau gambar. Pada penelitian ini, tipe humor yang diteliti oleh penulis adalah humor verbal yang disajikan dalam bentuk kartun (manga) dimana data penelitian diambil dari tuturan para tokoh dalam manga.

Berger (1992:83) mengkategori kan teknik humor ke dalam empat aspek, yakni bahasa, logika, identitas, dan tindakan. Berikut klasifikasi humor dari segi bahasa menurut Berger dari 16 teknik hanya 10 teknik yang ditemukan dalam penelitian ini yaitu :

1. Allusions (sindiran)

Sindiran dilakukan dengan mengungkit hal yang melekat pada seseorang secara umum.

2. Bombast (Bualan)

Pembualan adalah teknik humor yang tidak mensesuaikan apa yang harus diucapkan dengan bagaimana hal tersebut terucap.

3. Difinition (Definisi)

Humor berupa definisi yang mengandung elemen tipuan yang mampu mengubah definisi umum dari yang telah diketahui secara umum menjadi sesuatu yang diharap serius tetapi justru memunculkan canda.

4. Exaggerations(Melebih-lebihkan)

Humor dengan melebih-lebihkan selalu terikat dengan suatu topik lain sebagai dasar agar dapat dikembangkan panjang lebar hingga menjadi candaan.

5. Facetiousness (Jenaka)

Humor ini memiliki elemen ambiguitas dengan penyampaian yang dilakukan tanpa adanya keseriusan.

6. Infantilism (Kekanak-kanakan)

Memanipulasi kata dan suara, membolak balikkan kata, menyamarkan suara orang.

7. Insults (Hinaan)

Humor ini lebih mengutamakan rasa permusuhan. Menghina dapat dilakukan dengan membahagiakan.

8. Missunderstanding (Kesalahpahaman)

Kesalahpahaman terikat dengan masalah kebahasaan yang dapat dipengaruhi dari aspek verbal, pendengaran, atau memang pemaham yang kurang.

9. Puns, Worl Play, And Other Amalgamations (Permainan Kata)

Dengan permainan kata, maka dapat berubah hingga membuat tercengang.

10. Literalness (Harfiah) 
Humor ini berdasar pada ketidakmampuan seseorang dalam menerima atau memahami situasi hingga berekspresi tanpa memperhatikan norma.

\section{Penciptaan Humor}

Ada tiga teori utama, Ketiga teori yang semula berasal dari teori psikologi itu adalah teori pembebasan, teori konflik, dan teori ketidakselarasan (Wilson 1979:10). Teori pembebasan berkenaan dengan tipu daya emosional sepertinya mengancam, namun sebenarnya tidak. Teori konflik menekankan implikasi perilaku humor yaitu pertentangan antara dua dorongan, antara keramahan dan kebengisan atau antara main-main dan keseriusan. Teori ketidakselarasan dan bisosiasi menyangkut penggabungan dua makna atau dua interpretasi yang tidak sama terjadi sekaligus.

\section{Metode}

Jenis penelitian yang digunakan yaitu jenis deskriptif kualitatif karena menganalisis tentang pelanggaran maupun pematuhan maksim dalam prinsip kerjasama beserta teknik penciptaan humor dilihat dari segi kebahasaan di Jepang melalui manga. Seperti yang disimpulkan oleh Sugiono (2010:15) bahwa metode penelitian kualitatif deskriptif adalah metode penelitian yang berlandaskan filsafat postpositivisme, digunakan untuk meneliti kondisi objek yang alamiah, hasil penelitian kualitatif lebih menekankan makna daripada generalisasi.

Dalam penelitian ini menggunakan media berupa manga yang berjudul Tensai Bakabon ( 天才バカボン) Volume 2 karya Fujio Akatsuka yang merupakan sumber data utama. Manga dipilih sebagai sumber data dalam penelitian ini karena manga ini tergolong manga yang bergenre komedi yang menggunakan bahasa dalam memunculkan kelucuan-kulucuan di dalamnya.

Metode pengumpulan yaitu metode simak dan catat, metode simak. Metode simak di sini tidak hanya berkaitan dengan penggunaan bahasa secara lisan, tetapi juga penggunaan bahasa secara tertulis. Menurut Mahsun (2005:90) metode simak merupakan cara pengumpulan data yang dilakukan dengan cara menyimak penggunaan bahasa.

Proses analisis yang digunakan dalam penelitian ini ialah dengan menggunakan model Miles dan Huberman (1992:58) yaitu Data Reduction (Reduksi Data), Data Display (Penyajian Data), Conclusion Drawing (Penarikan Kesimpulan), triangulasi.

\section{Hasil dan Pembahasan}

Data yang ditemukan pada penelitian ini sebanyak 28 data yaitu 26 data pelanggaran dan 2 data pematuhan prinsip kerjasama yang dapat memunculkan humor pada komik Tensai Bakabon Volume 2. Pelanggaran terhadap prinsip kerjasama lebih banyak ditemukan yaitu 2 data maksim kuantitas, 9 data maksim kualitas, 8 data maksim relevansi, dan 7 data maksim cara. Sedangkan pematuhan terhadap prinsip kerjasama hanya terdapat 2 data yaitu 2 data maksim cara yang ditemukan.

\section{Pelanggaran Prinsip kerjasama \\ Pelanggaran Maksim Relevansi}

Pelanggaran pada maksim ini juga menggunakan teknik penciptaan humor, salah satunya teknik kesalahpahaman sekaligus teknik kekanak-kanakan seperti yang terlihat pada contoh berikut :

Bakabon : 隊長 !

Taichou!
'kapten'
Papa $\quad$ なんだ部下?
Nanda buka?
'Ada apa anak buah ?'
Bakabon : あ、ほくのことバカといったな。
A, boku no koto baka to ittana.
'Ah, papa panggil aku baka (bodoh).' (1)




\section{Papa : ブカ！バカといったの！いやそのはんたい！ Buka! Baka to itta no! lya sono hantai! 'Buka (anak buah) !aku panggil kamu baka (bodoh)! Eh, terbalik.' (2)}

Pada tuturan (1) teknik penciptaan humor yang digunakan yaitu teknik kesalahpahaman. Efek lucu pada tuturan tersebut yaitu terihat pada kata 'ぶか' (buka=anak buah) yang terdengar 'ばか' (baka=bodoh). Dalam penggalan tuturan tersebut terdapat permainan bahasa dalam bidang fonologi yaitu adanya perubahan bunyi 'ぶ' (bu) menjadi ‘ば ' (ba) yang mengakibatkan kesalahpahaman antara tokoh. Ketika akan mengkonfirmasi Papa justru membolak balikkan perkataanya yaitu pada tuturan (2) dengan menggunakan teknik kekanak-kanakan dalam pembentukan humornya. Hal ini dianggap lucu karena timbul dari kesalahan yang dilakukan Papa yang menggoda Bakabon.

Pada tuturan (1) melanggar maksim relevansi karena memberikan jawaban yang tidak sesuai dengan pertanyaan Papa. Bakabon tidak memperdulikkan pertanyaan Papa dan justru bertanya kembali kepada Papa, maka sumbangan informasi yang diberikan Bakabon tersebut tidak ada korelasinya dengan topik yang akan dibicarakan Papa.

Selain teknik kesalahpahaman sekaligus teknik kekanak-kanakan, pada pelanggaran maksim ini juga menggunakan teknik harfiah yaitu pelanggaran komunikasi yang diakibatkan oleh hal yang sama yaitu tokoh Papa yang tidak memberikan kontribusi yang relevan dalam percakapan, namun dalam menciptakan humor, percakapan dibawah ini menggunakan teknik harfiah karena Papa tidak memahami situasi yang sedang terjadi. Hal ini dianggap lucu karena menekankan implikasi perilaku humor antara Mama yang serius dengan Papa yang main-main.

(konteksnya, Mama yang memarahi Papa karena melukis wajah Mama dan Hajime dengan sangat buruk)

Mama :絵はぜったいゆるしません。

E wa zettai yuru shimasen.

'Mama benar-benar tidak mengizinkan Papa melukis lagi' (sambil membakar lukisan Papa)

Papa :こんどはやきいも屋さんになるぞ

Kondo wa yasaimo ya san ni naru zo.

'Lain kali akan jadi pedagang ubi bakar saja' (sambil membawa ubi untuk dibakar ditempat mama membakar lukisan)

\section{Pelanggaran Maksim Kualitas}

Pelanggaran pada maksim ini juga menggunakan teknik penciptaan humor salah satunya yaitu teknik hinaan seperti pada contoh dibawah ini :

(Percakapan terjadi antara Pensuke dan Asako saat berjumpa di taman)

Pensuke : よう！ポリバケツのアサ公じやねえかよ。

You! Pori baketsu no Asakou janeka yo.

'Hei! Asakou si ember plastik.' (1)

Asakou : あ! ガード下のペンすけ。。

A! gado shita no pensuke..

'Eh Pensuke si kolong jembatan' (2)

Tuturan (1) dan (2) memunculkan kelucuan dengan teknik hinaan, karena Asakou maupun Pensuke mengucapkan kata-kata tersebut bertujuan menghina satu sama lain untuk membahagiakan diri masing-masing. Hal ini dianggap lucu karena menekankan implikasi perilaku humor yaitu pertentangan dua dorongan, keramahan dan kebengisan. Dikatakan keramahan karena tuturan hinaan tersebut digunakan untuk mengakrabkan diri antara yang satu dengan yang lainnya, sedangkan disebut kebengisan karena pemilihan kata yang digunakan dalam bertutur terlalu berlebihan sehingga terkesan kejam. 
Tuturan (1) dan (2) tersebut melanggar maksim kualitas karena mereka berdua bertutur tidak sesuai dengan fakta yang ada. Faktanya kedua penutur tersebut adalah seorang manusia bukan kolong jembatan atau ember plastik.

Selain menggunakan teknik hinaan, pelanggaran pada maksim ini juga menggunakan teknik melebih-lebihkan. Seperti pada tuturan dibawah ini memunculkan teknik melebih-lebihkan dengan memunculkan majas hiperbola (melebih-lebihkan suatu hal) yang tujuannya hanya untuk kebohongan semata yang hal tersebut justru dianggap lucu. (konteks, ketika Nonchan bertamu kerumah Mama dan memamerkan Parfumnya yang dibeli dari prancis)

Non chan : あなたちょっとおフランスへお香水買いにいけば

Anata chotto ofuransu e okousui kai ni ikeba.

'Kamu bisa beli parfumnya juga pergi saja ke prancis.

Mama : とんでもないっ

Tondemonai.

'Ah tidak mungkin'

Non chan : あ、そうそう私アメリカへおコロッケ買いにいかなくちゃ！

A, sou sou watashi Amerika e okorokke kai ni ikanakucha!

'Baru ingat, aku harus pergi ke Amerika dulu beli kroket (sejenis perkedel)'

\section{Pelanggaran Maksim Kuantitas}

Pada pelanggaran maksim ini, menggunakan teknik definisi sekaligus teknik jenaka dalam memunculkan humor. Seperti pada contoh percakapan berikut :

(Percakapan Papa, Bakabon dan Pujangga dalam menebak sajak)

Papa : ああ、七五三のあれか。

Aa, sichi go san are ka.

'Aa, 753 kan.' (1)

Pujangga : 七五三はお祝いじゃ!

Sichi go san wa oiwai ja!

'Itu hari perayaan anak diumur 7,5,3 tahun'

Papa : じゃO○七だ。

Ja zero zero sichi da.

'Kalau begitu 007 ya.' (2)

Pujangga : それは殺しのばんっごう。 Sore wa koroshi no bangou.

'Itu nomor telepon agen rahasia.'

Papa : じゃーーOか !

Ja ichi ichi zero ka!

'Kalau begitu 110!' (3)

Bakabon：それは警察だよ。

Sore wa keisatsu da yo.

'Itu nomor polisi.'

Pujangga : 知ったかぶりはよしなさい。俳句は五七五じゃ。 Shitakaburi wa yoshinasai. Haiku wa go sichi go ja. 'Jangan pura pura tahu padahal tidak tahu. kalau sajak itu 575.'

Papa : ハハハ知ってたけどわざとふさけたんですよ。

Ha ha ha shitetakedo waza to fusaketan desu yo.

'Hahaha saya sudah tahu tapi pura-pura tidak tahu'(4)

Pujangga : うそ!

Uso.

'Bohong !'

Tuturan Papa pada percakapan $(1,2,3)$ memunculkan kelucuan dengan teknik definisi. Diketahui secara umum aturan persajakan menggunakan 3 angka yaitu 575. Papa memang menyebutkan tiga angka sebagai jawaban dari pertanyaan pujangga, namun tiga 
angka yang diucapkan tersebut tidak ada hubungannya dengan persajakan. Seperti nomor polisi 110, nomor agen rahasia 007 dan angka peringatan anak diusia 7,5,3. Hal ini dianggap lucu karena angka-angka yang disebutkan Papa dan angka yang ditujukan untuk persajakan merupakan dua entitas yang secara asosiatif terlampau berjauhan. Setelah itu Papa mengatakan hal yang membuat kemarahan pujangga sedikit mereda. Seperti pada tuturan (4) yang menimbulkan efek humor dengan menggunakan teknik jenaka. Hal tersebut dianggap lucu karena Papa menyampaikan tuturannya tanpa adanya keseriusan yang digunakan sebagai simbol pembebasan ketegangan karena kemarahan pujangga.

Tuturan Papa tersebut melanggar maksim kuantitas karena informasi yang diberikan Papa melebihi informasi yang diinginkan si pujangga. Keinginan Pujangga hanyalah tiga angka persajakan bukan tiga angka selain itu sehingga ketika Papa mengatakan tiga angka lainnya hal tersebut melebihi informasi yang diinginkan lawan tutur.

\section{Pelanggaran Maksim Cara}

Pelanggaran terhadap maksim ini, menggunakan teknik kekanak-kanakan dalam memunculkan humor seperti pada contoh berikut :

(Percakapan antara Pria 1 dan So kun tentang pemberangkatan ke planet Apiyon)

Pria 1 :ソくん！さいごの探検隊を出そうではないの!

So kun! Saigo no tankentai o da sou dewanai no!

'So kun! Coba kirim tim inspeksi yang terakhir yuk !'

\section{So kun :さんせいのはんたいでさんせい!}

\section{Sansei no hantai de sansei!}

'Kebalikannya tidak setuju jadi setuju'

Tuturan 'Sansei no hantai de sansei' yang berarti 'Kebalikannya tidak setuju jadi setuju' memunculkan kelucuan dengan teknik kekanak-kanakan karena membolak balikkan kata. Humor tersebut dilakukan atas pengaruh sifat anak-anak yang tetap dipertahankan dalam kehidupan masa dewasa. Seperti menirukan anak-anak yang gembira dengan bermain kata. Hal ini dianggap lucu karena dapat digunakan sebagai simbol pembebasan ketegangan.

Tuturan tersebut melanggar maksim cara karena mengatakan sesuatu dengan terbolak balik, tidak langsung kepada intinya sehingga terkesan berbelit-belit dan tidak jelas.

Selain teknik kekanak-kanakan juga terdapat teknik permainan kata seperti pada percakapan dibawah ini :

(konteks, ketika Papa dan narator ketika Papa terpilih menjadi perwakilan yang akan menuju ke planet Apiyon)

Papa : せんぽつたいいんのしょうぞくをかならずや。

Senpotsu taiin no syouzoku o kanarazuya.

'Saya pasti menemukan anggota yang dahulu'

Narator: 難しいことば。

Muzukashii kotoba.

'Pemilihan katanya sulit sekali'

Papa : かならずや、わからずや,やおやにサカナやアピヨーン、ピヨンでありますっ。

Kanarazu ya, wakarazu ya, yao ya ni sakana ya apiyon piyon de arimasu.

'Pasti, keras kepala, toko sayur, toko ikan, ada apiyon, piyon.'

Narator：きみらは隊員にふさわしい!

Kimira wa taiing ni fusawashii.

'Memang kalian orang yang tepat untuk anggota ini.'

Pada tuturan yang dicetak tebal di atas, dalam memunculkan kelucuan teknik permainan kata karena Papa mempermainkan kata-kata yang diungkapkannya. Kata pertama dan kedua yang diucapkan diawal kalimat merupakan kata yang mengesankan, namun kemudian Papa justru mengatakan 'yao ya' yang berarti toko sayur, 'sakana ya' yang berarti toko ikan yang jelas-jelas tidak ada hubungannya dengan ucapan sebelumnya yang pemilihan katanya begitu luar biasa, sehingga membuat narator tercengang, namun setelah 
ditambahkan dengan kata lain yang berakhiran 'や”ya' yaitu 'yao ya' yang berarti toko sayur, 'sakana ya' yang berarti toko ikan narator berfikir memang Papa adalah orang yang cocok dengan program tersebut. Efek lucu pada tuturan di atas terlihat pada kata 'や'ya'. Dalam penggalan tuturan tersebut digolongkan sebagai permainan bahasa dalam bidang polisemi karena 'や'ya' pada kata pertama dan kedua memiliki arti 'dan' namun pada bagian selanjutnya 'や'ya' memiliki arti 'toko'. Hal inilah yang menimbulkan kelucuan bagi para pembaca.

Tuturan Papa melanggar maksim cara karena Papa mengatakan sesuatu dengan tidak jelas. Apa yang dimaksud Papa tidak dipahami oleh narator membuatnya bingung dan menganggap Papa adalah orang yang bodoh karena mengatakan sesuatu dengan tidak jelas. Hal tersebut di dukung dengan tuturan narator 'Kimira wa taiin ni fusawashii.' yang berarti 'memang kalian orang yang tepat untuk program ini'. Narator menyiratkan maksud bahwa Papa adalah orang yang Bodoh karena program tersebut dibuat untuk orang terbodoh di Jepang.

\section{Pematuhan Prinsip Kerjasama \\ Pematuhan Maksim Cara}

Pada pematuhan maksim ini, menggunakan teknik penciptaan humor yaitu teknik harfiah seperti contoh berikut :

(Percakapan Papa dan tamu ketika akan menginap)

Papa： 家ができるまでうちにすんでもらう。

le ga dekiru made uchi ni sunde morau.

Mama

'Dia mau numpang sampai rumahnya selesai.'

\section{Tamu : ぜんぜんえんりょしないからねつ。 \\ Zenzen enryo shinaikara ne. \\ 'Sama sekali tidak akan malu-malu.' \\ (sambil berguling-guling dilantai)}

Tuturan 'Zenzen enryo shinaikara ne' yang berarti 'Sama sekali tidak akan malumalu' memunculkan kelucuan dengan menggunakan teknik harfiah karena tamu tersebut tidak mampu memahami situasi sehingga berekspresi tanpa memperhatikan norma. Ketika bertamu dirumah seseorang akan dianggap tidak sopan ketika belum dipersilahkan namun sudah menuturkan bahwa dirinya tidak akan malu-malu berada dirumah tersebut. Hal ini dianggap lucu karena merupakan sesuatu yang menggelikan dan di luar kebiasaan.

Tuturan 'Zenzen enryo shinaikara ne' yang berarti 'Sama sekali tidak akan malumalu' mematuhi maksim cara karena tamu dengan polosnya mengatakan sesuatu hal dengan sangat jelas dan dapat dipastikan setiap tuturannya dimengerti oleh Papa maupun keluarga Papa. Tamu mengatakan 'sama sekali tidak akan malu-malu', sudah jelas tamu tersebut akan bersikap seperti ia sedang berada dirumahnya sendiri dan tidak sungkan dalam melakukan hal apapun. Ini terbukti ketika belum dipersilahkan untuk menginap namun tamu tersebuh sudah berguling-guling di rumah keluarga Papa.

Selain teknik harfiah pada pematuhan prinsip ini juga menggunakan teknik jenaka dalam memunculkan kelucuan, munculnya teknik jenaka pada tuturan dibawah ini, disebabkan oleh dosen yang bertutur dengan mempermainkan jawaban dari siswanya yang sudah dengan serius mencari jawaban namun ditanggapi dengan berkelakar oleh dosen. Hal tersebut dianggap lucu karena menekankan implikasi antara dua dorongan yaitu keseriusan dan main-main.

(konteksnya, Dosen dan mahasiswa tentang air laut)

Dosen: 海の水はなぜしょぱっい?

Umi no mizu wa naze shoppai ?

'Kenapa air laut asin ?'

Mahasiswa: 塩化ナトリウム、塩化カリウムそれに塩化マグネシュウム。。。 Enka natoriumu, enka kariumu, soreni enka maguneshuumu... 
'Karena mengandung natrium klorida, kalium klorida, magnesium klorida...'

Dosen : ちがう！海の水はなぜしょっぱい?それはなめてみたからさ。 Chigau ! umi no mizu wa naze shoppai ? sore wa namete mita kara sa.

'Salah ! kenapa air laut asin? ya karena abis jilat.'

Dosen :つまりなめてみなけりや味はわからないのである。Tsumari namete minakari ya aji wa wakaranai no de aru.

'kalo gak dicoba kan gak tau rasanya.

\section{Simpulan dan Saran}

Penelitian ini meneliti tentang pragmatik khususnya meneliti tentang pelanggaran dan pematuhan prinsip kerjasama yang dapat menciptakan efek humor dalam manga. Penelitian ini berfokus pada tuturan dalam manga Tensai Bakabon volume 2 karya Fujio Akatsuka. Hal yang diteliti dalam penelitian ini yaitu tentang bentuk pelanggaran maupun pematuhan maksim dalam prinsip kerjasama dan teknik yang digunakan untuk menciptakan sebuah humor yang disertai dengan konteks situasi tutur untuk mempermudah mengetahui tuturan yang mampu menciptakan efek humor.

\section{Daftar Pustaka}

Berger, Arthur Asa.1992.An Anatomy of Humor.New Jersey:Transation Publishers.

Brown, G dan Yule G.1988.Discourse Analysis.Cambridge:Cambridge University Press.

Bussman, Hadumod.1996. Dictionary of Language an Linguistic.London:Routledge.

Chaer, Abdul dan Agustina Leonie.2004.Sosiolinguistik:Perkenalan awal.Jakarta:Rineka Cipta.

Clements, Jonathan dan Helen McCarthy.2006. The Anime Encyclopedia:A Guide to Japanese Animation Since 1917.Stone Bridge Press:Titan Books.

Ensiklopedi Indonesia.1982.Jakarta:Ikhtisar Baru-Van Hoeve.

Grice, H.P.1975. Syntax And Semantics 3: Speech Acts: Logic and Conversation.New York:Oxford University Press.

Hamlyn.1995. Humor Contemporary Junior Literature.New York:Routledge Publishers.

Hayashi, Ooki.1990. Nihongo Kyooiku Handobukku.Tokyo:Taishuukan Shoten.

Koizumi,Tamotsu.2001.Nyuumon Goyouron Kenkyuu:Riron to Ouyou.Tokyo:Kenkyuusha.

Kamus Besar Bahasa Indonesia Online.http://kbbi.web.id/komik.2012.diakses pada 20 juli 2017.

Nadar,F.X. 2009. Pragmatik dan PenelitianPragmatik.Yogyakarta:Graha Ilmu.

Mahsun.2005.Metode Penelitian Bahasa: Tahapan Strategi, Metode dan

Tekniknya.Jakarta:Raja Grafindo Persada.

Rani, Abdul, dkk.2004.Analisis Wacana.Jawa Timur:Bayumedia Publishing.

Sugiono.2010.Metode Penelitian Pendidikan:Pendekatan Kualitatif,Kuanitatif dan $R \& D$.Bandung:Alfabeta.

Wilson, C.1979. Jokes: From, Content, Use, and Function.New York:Academic Press. 
JPBJ, Vol. 4 No. 2, Juli, 2018

ISSN: 2613-9618

Wijana, I Dewa Putu dan Muhammad Rohmadi.2010.Analisis Wacana Pragmatik,kajian teori dan analisis.Surakarta:Yuma Pustaka.

Yule, George.1996.Pragmatics.New York:Oxford University Press 